\title{
SIMULATIONS OF THERMAL PROCESSES IN A RESTORED TOOTH
}

\author{
Jarosław Siedlecki ${ }^{1}$, Mariusz Ciesielski ${ }^{2}$ \\ ${ }^{I}$ Institute of Mathematics, Czestochowa University of Technology \\ ${ }^{2}$ Institute of Computer and Information Sciences, Czestochowa University of Technology \\ Częstochowa, Poland \\ ${ }^{1}$ jaroslaw.siedlecki@im.pcz.pl, ${ }^{2}$ mariusz.ciesielski@icis.pcz.pl
}

\begin{abstract}
In this paper the analysis of the temperature distribution in restored tooth is considered. The aim of the research is to evaluate the impact of temperature changes in the pulp layer of tooth under the influence of rapid temperature changes in the ambient fluid. The axially-symmetrical model of the molar tooth (in vitro) without filling and with fillings (amalgam and composite resin) is analyzed. The equations of mathematical model are solved numerically using the control volume method. Finally, some examples of simulations are presented.
\end{abstract}

Keywords: restored tooth, thermal process, numerical solution

\section{Introduction}

Restorative materials [1] are often used to obturate dental cavities. The filled tooth may be sensitive to heat and cold. Temperature fluctuations occur in the oral cavity due to the ingestion of cold or hot food and drink. The tooth has many layers [2]: enamel (the outer layer is made of hard crystal), dentin (the layer is the bonelike substance) and pulp (in the middle of the tooth). The dental pulp contains nerves (also blood vessels) and it is very sensitive to temperature change. The pulp in the healthy tooth is surrounded by enamel and dentine, which are good thermal insulators.

Dental fillings can be made from many types of material [1,3]. The amalgam fillings (a mixture of mercury, silver, tin, or other metals) is the easiest and least costly material for a dentist to use. The composite resin fillings (a mixture of powdered glass and plastic resin) can look similar to the appearance of the natural tooth (white fillings). These fillings are usually more expensive than the amalgam fillings. Materials used to restore teeth should offer a similar degree of insulation. Additionally, these materials should not produce a large temperature rise when setting in cavities - a similar problem regarding to exothermic photopolymerization reaction was considered in [4].

In this paper the research related to determine the temperature distribution in the tooth are considered. The axially-symmetrical model of the molar tooth (in vitro) 
is placed in the external environment (in vitro), i.e. the tooth crown is in contact with the surrounding liquid of variable temperature, and the tooth root is isolated. On the base of these assumptions the mathematical model for the thermal process in the tooth without fillings and with fillings is developed. The aim of the research is to determine the temperature changes in the pulp layer of the tooth with different filling materials under the influence of the same boundary conditions.

\section{Mathematical model}

The tooth cylindrical domain considered in Figure 1 is presented. The domain consists of many sub-domains: the enamel $\left(\Omega_{1}\right)$, the dentin $\left(\Omega_{2}\right)$ and the pulp $\left(\Omega_{3}\right)$. In the case of the tooth model with restoration, the additional sub-domain $\left(\Omega_{4}\right)$ is taken into account. On the outer surface limiting the domain $\left(\Gamma_{b 1}\right.$ and $\left.\Gamma_{b 4}\right)$, a fluid having a certain temperature and playing a role of an external chill or warm is assumed. The boundary $\Gamma_{0}$ represents the contact with the gum.

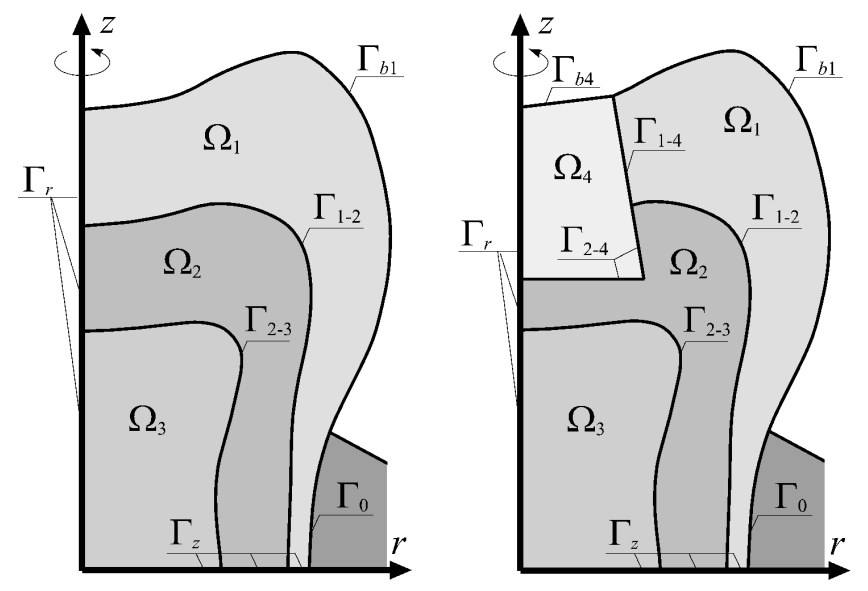

Fig. 1. The tooth domain considered (the cylindrical cross-sections): without restoration (left-side) and with restoration (right-side)

The temperature field in the system of each sub-domain is described by the system of equations

$$
c_{m} \rho_{m} \frac{\partial T_{m}(r, z, t)}{\partial t}=\lambda_{m}\left(\frac{1}{r} \frac{\partial}{\partial r}\left(r \frac{\partial T_{m}(r, z, t)}{\partial r}\right)+\frac{\partial^{2} T_{m}(r, z, t)}{\partial z^{2}}\right), \quad m=1,2,3,4
$$

where index $m$ identifies the particular sub-domains ( 1 - the enamel, 2 - the dentin, 3 - the pulp, 4 - the dental restoration material), $T\left[{ }^{\circ} \mathrm{C}\right]$ is the temperature, $r, z[\mathrm{~m}]$, $t[\mathrm{~s}]$ denote spatial coordinates and time, $c\left[\mathrm{~J} /\left(\mathrm{kg}{ }^{\circ} \mathrm{C}\right)\right], \rho\left[\mathrm{kg} / \mathrm{m}^{3}\right], \lambda\left[\mathrm{W} /\left(\mathrm{m}{ }^{\circ} \mathrm{C}\right)\right]$ are the specific heat, the density and the thermal conductivity of materials considered, respectively. 
The Eq. (1) is supplemented by the following initial-boundary conditions. For $t=0$ the initial condition is known

$$
\left.T_{m}(r, z, t)\right|_{t=0}=T_{\text {init }}, \quad m=1,2,3,4
$$

On the contact surfaces between sub-domains, the IV type of boundary conditions are assumed

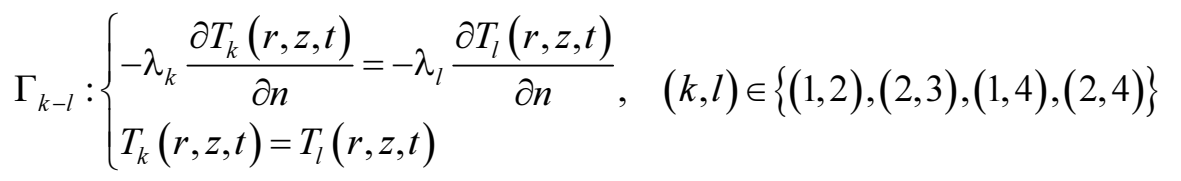

where $\partial / \partial n$ is a normal derivative. On the external surface of the sub-domains $\Omega_{1}$ and $\Omega_{4}$, the II type (on the surface of the tooth root $-\Gamma_{0}$ ) and III type (on the surface of the tooth crown $-\Gamma_{1 m}$ and $\Gamma_{4 m}$ ) of boundary conditions are given

$$
\begin{gathered}
\Gamma_{b m}:-\lambda_{m} \frac{\partial T_{m}(r, z, t)}{\partial n}=-\alpha\left(T_{a m b}(t)-T_{m}(r, z, t)\right), \quad m=1,4 \\
\Gamma_{0}: \frac{\partial T_{1}(r, z, t)}{\partial n}=0
\end{gathered}
$$

where $\alpha\left[\mathrm{W} /\left(\mathrm{m}^{2}{ }^{\circ} \mathrm{C}\right)\right]$ is the convective heat transfer coefficient and $T_{a m b}\left[{ }^{\circ} \mathrm{C}\right]$ is the temperature of the ambient fluid. In the mathematical model the following simplifications are assumed: the temperature of fluid declines or grows according to a given function, the heat transfer coefficient is treatment as a constant (depends on many parameters: especially the fluid velocity, the surface geometry, the nature of motion, etc.). While on the boundaries $\Gamma_{r}$ and $\Gamma_{z}$, the non-flux boundary conditions are given in the form

$$
\begin{gathered}
\Gamma_{r}:\left.\frac{\partial T_{m}(r, z, t)}{\partial r}\right|_{r=0}=0, \quad m=1,2,3,4 \\
\Gamma_{z}:\left.\frac{\partial T_{m}(r, z, t)}{\partial z}\right|_{z=0}=0, \quad m=1,2,3
\end{gathered}
$$

\section{Examples of computations}

Three numerical simulations of a thermal process for the tooth without restoration and with two different dental materials restoration have been executed. 
At the stage of numerical computations, the control volume method $[5,6]$ has been used. The control volumes for the considered cylindrical domain are in the shape of rings. The sizes of considered domains of the tooth model and the control volume meshes (the cylindrical cross-sections) used in computations in Figure 2 are presented.
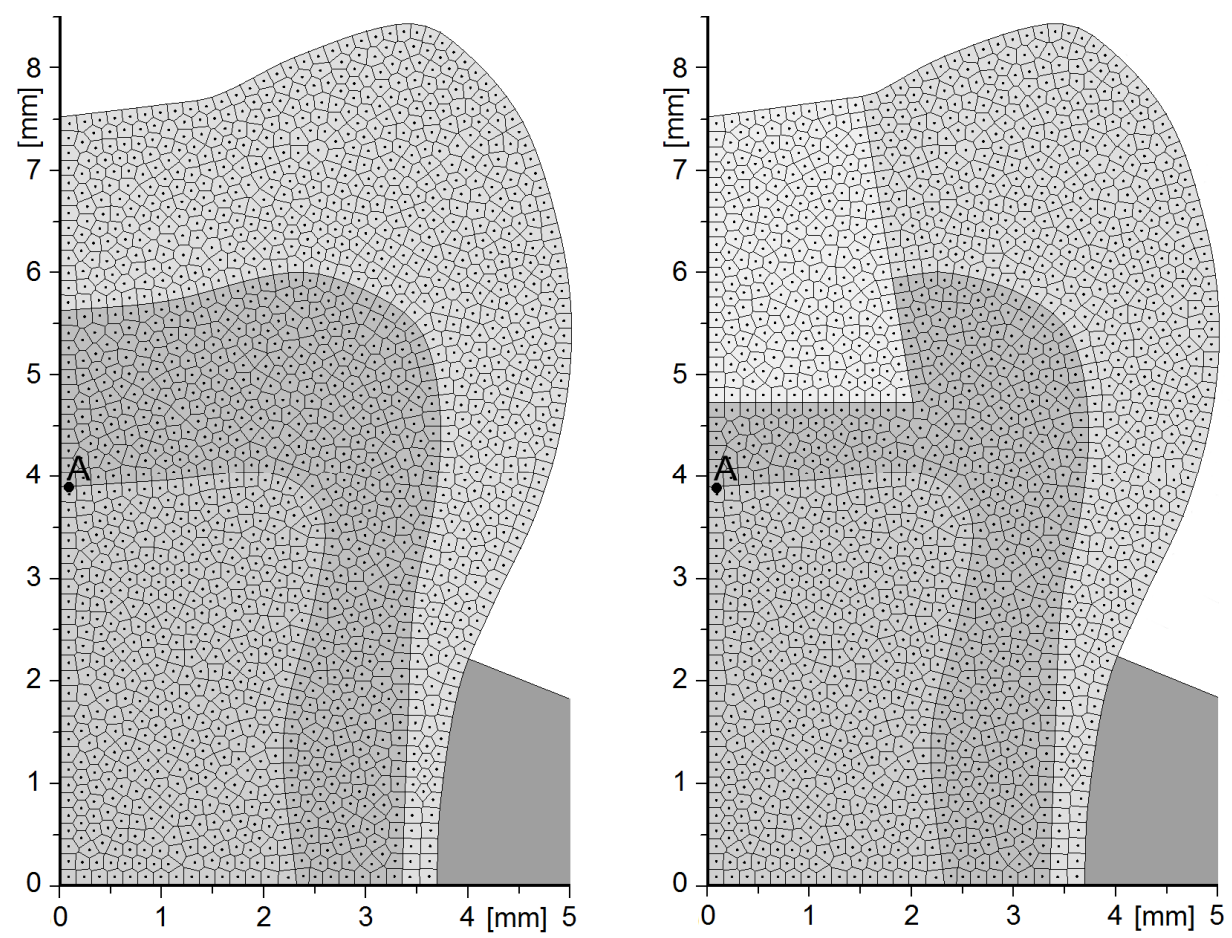

Fig. 2. The control volume meshes in cross-sections of the tooth model: without restoration (left-side) and with restoration (right-side)

The following thermophysical parameters of the tooth layers have been assumed [7]: $c_{1}=750, c_{2}=1170, c_{3}=4200 \mathrm{~J} /(\mathrm{kg} \mathrm{K}), \rho_{1}=2900, \rho_{2}=2100, \rho_{3}=1000 \mathrm{~kg} / \mathrm{m}^{3}$, $\lambda_{1}=0.92, \lambda_{2}=0.63, \lambda_{3}=0.59 \mathrm{~W} /(\mathrm{m} \mathrm{K})$, while thermophysical parameters of two dental restoration materials are the following: for the amalgam $c_{4}=240 \mathrm{~J} /(\mathrm{kg} \mathrm{K})$, $\rho_{4}=10500 \mathrm{~kg} / \mathrm{m}^{3}, \lambda_{4}=22.68 \mathrm{~W} /(\mathrm{m} \mathrm{K})$, and for the composite material (Adaptic): $c_{4}=820 \mathrm{~J} /(\mathrm{kg} \mathrm{K}), \rho_{4}=1960 \mathrm{~kg} / \mathrm{m}^{3}, \lambda_{4}=1.1 \mathrm{~W} /(\mathrm{m} \mathrm{K})$. The initial temperature is $T_{\text {init }}=36.6^{\circ} \mathrm{C}$, the temperature of the ambient fluid is $\mathrm{T}_{\text {amb }}(t)=\min (5+3 t, 36.6)$ ${ }^{\circ} \mathrm{C}$ and the heat transfer coefficient is $\alpha=500 \mathrm{~W} /\left(\mathrm{m}^{2}{ }^{\circ} \mathrm{C}\right)$.

In Figures 3 and 4 the isotherms in the tooth sub-domains for time points: $2 \mathrm{~s}$ and $5 \mathrm{~s}$ are shown, respectively. The kinetics of temperature variation at the selected point lying on the connection of the pulp and dentin sub-domains in Figure 5 is presented. 


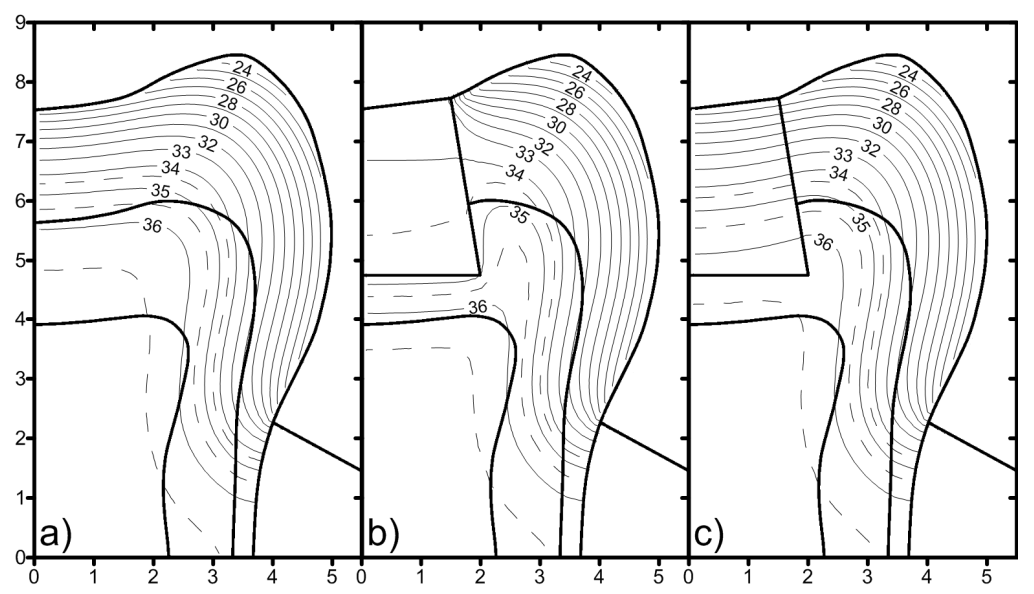

Fig. 3. Temperature distribution in sub-domains at time $2 \mathrm{~s}$ : a) tooth without restoration, b) amalgam restoration, c) composite material restoration

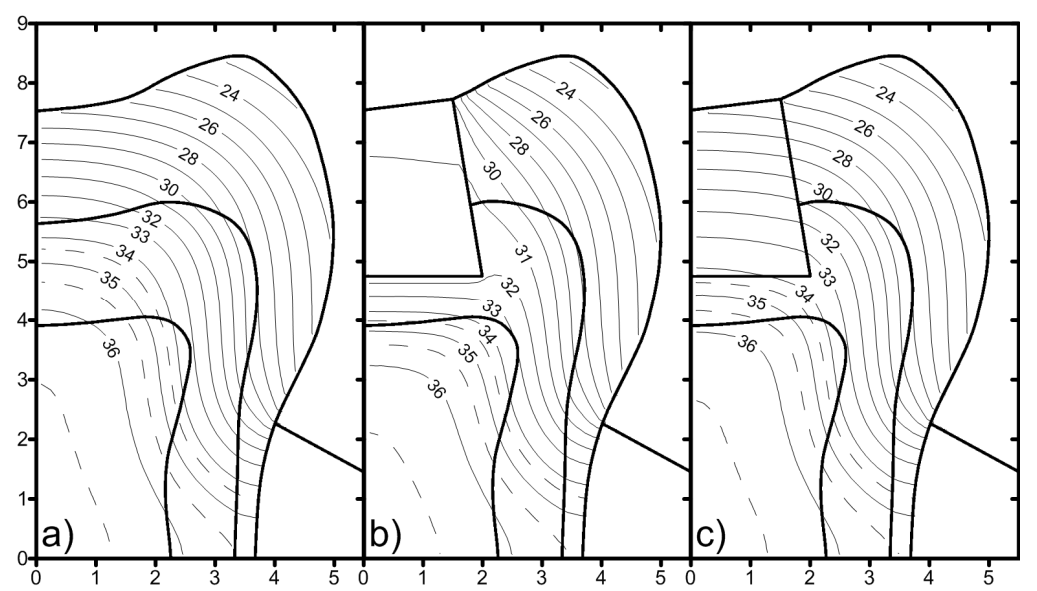

Fig. 4. Temperature distribution in sub-domains at time $5 \mathrm{~s}$ : a) tooth without restoration, b) amalgam restoration, c) composite material restoration

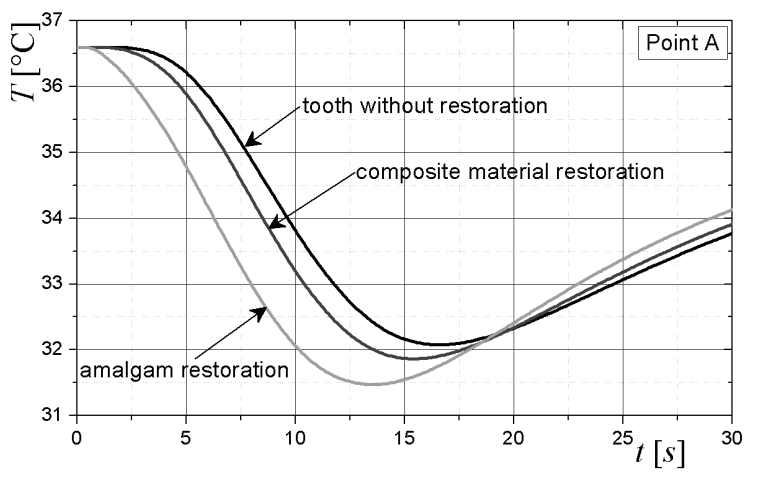

Fig. 5. The kinetics of temperature variation at selected point A (see Fig. 2) 


\section{Conclusions}

The control volume meshes used in numerical simulations quite accurately determine the geometry of the cylindrical section of the tooth model. Analyzing the kinetics of temperature variation for each type of filling one can note that the amalgam restoration conducts heat very quickly and causes the fastest decrease of temperature in the pulp. In the case of the composite material restoration in the tooth the temperature distribution is similar to the temperature distribution in the tooth without restoration.

\section{References}

[1] McCabe J.F., Walls A., Applied Dental Materials, Wiley-Blackwell, 2008.

[2] Scheid R., Weiss G., Woelfel's Dental Anatomy: Its Relevance to Dentistry, Ed. 8, Lippincott Williams \& Wilkins, 2011.

[3] Spierings Th.A.M., De Vree J.H.P., Peters M.C.R.B., Plasschaert A.J.M., The influence of restorative dental materials on heat transmission in human teeth, Journal of Dental Research 1984, 63, 1096-1100.

[4] Siedlecki J., Ciesielski M., Mathematical model for thermal processes in photopolymerization, Scientific Research of the Institute of Mathematics and Computer Science 2012, 4(11), 113-119.

[5] Mochnacki B., Suchy J.S., Numerical Methods in Computations of Foundry Processes, Polish Foundrymen's Technical Association, Cracow 1995.

[6] Szopa R., Siedlecki J., Modelling of solidification using the control volume method, Solidification of Metals and Alloys 2000, 44(2), 349-354.

[7] Jakubinek M.B., et al., Temperature excursions at the pulp-dentin junction during the curing of light-activated dental restorations, Dental Materials 2008, 24, 1468-1476. 